\title{
PENGARUH USIA IBU HAMIL TERHADAP KEJADIAN PLACENTA PREVIA DI RSUP SOERADJI TIRTONEGORO
}

\author{
Yeni Tutu Rohimah \\ Politeknik Kesehatan Surakarta Jurusan Keperawatan
}

\begin{abstract}
Maternal Age, Placenta Previa. Maternal Mortality Rate (MMR), is one of State Health Development Indicators. Indonesia MMR in the first level in Asean. Bleeding is the cause of MMR,placenta Previa is cause of bleeding, the incidence of placenta previa is $0.3-0.5 \%$ of all births, the risk of placenta previa associated with age of the women during pregnancy. Incidence increased as follows : 12-19 years - 1\%, 2029 years $-0.33 \%, 30-39$ years $-1 \%$, above 40 years - $2 \%$. Incidenceof placenta previa in Soeradji Tirtonegoro HospitalKlaten in 2010 there were 122 cases. Thestudyused the Ex Post Facto, the population in this study is the maternal with plecentaprevia, the sample used a total sample of 122 maternal with placenta previa in 2010. Devendent variable in this study is placenta previa, independt variable is the maternal age, the studyin Dr Soeradji Tirtonegoro Hospital Klaten. Analysis used the linear regression.The effect of maternal age on the incidence of plcentsprevisis significantp = 0.000 ( $p<0.05$ ), 87.20\% incidence of placenta previa is influenced by maternal age and the effect is very strong $r=0.938$. Each additional 1 year of maternal age increases the incidence of placenta previa 1,332 cases
\end{abstract}

Key Words : Maternal Age, Placenta Previa

Abstrak : Usia Ibu ibu hamil, Placenta Previa. Angka Kematian Ibu (AKI), merupakan salah satu indikator pembangunan kesehatan dasar suatu Negara. Di Indonesia AKI masih memprihatinkan dan menduduki peringkat pertama di Negara Asean. Perdarahan merupakan penyebab AKI yang paling utama, salah satu penyebab perdarahan adalah placenta previa, angka kejadian plasenta previa adalah 0,3-0,5\% dari semua kelahiran, resiko plasenta previa berhubungan dengan usia ibu saat hamil, kejadiannya meningkat sebagai berikut Usia 12-19 tahun - 1\%, usia 20-29 tahun 0,33\%, usia 30-39 tahun - 1\%, usia di atas 40 tahun - 2\%. Data kejadian placenta previa di Rumah Sakit Soeradji Tirtonegoro Klaten pada tahun 2010 terdapat 122 kasus. Jenis penelitian ini adalah Ex Post Facto, populasi pada penelitian ini adalah ibu melahirkan dengan plecenta previa, sample yang digunakan adalah total sampel yaitu sebanyak 122 ibu yang melahirkan dengan placenta previa pada tahun 2010. Variabel devenden pada penelitian ini adalah placenta previa sedangkan variable indevenden adalah usia ibu hamil, tempat penelitian RSUP Dr Soeradji Tirtonegoro Klaten, Analisa data yang digunakan adalah regresi linear dengan menggunakan SPSS for windows versi 13. Hasil penelitian ada pengaruh usia ibu saat hamil dengan kejadian placenta previa $\mathrm{p}=0,000$ ( $\mathrm{p}<0,05$ ), 87,20\% kejadian placenta previa dipengaruhi oleh usia ibu dan pengaruhnya sangat kuat $r=0,938$. Setiap penambahan usia ibu 1 tahun kejadian placenta previa bertambah 1,332 kejadian. 
Kata Kunci : Usia Ibu ibu hamil, Placenta Previa

\section{PENDAHULUAN}

Angka Kematian Ibu (AKI), merupakan salah satu indikator pembangunan kesehatan dasar suatu Negara. Di Indonesia AKI masih memprihatinkan dan menduduki peringkat pertama di Negara Asean. dari Survei Demografi dan Kesehatan Indonesia (SDKI) tahun 2007, Angka Kematian Ibu 228 per 100.000 kelahiran hidup. Tahun 2008, 4.692 ibu meninggal pada masa kehamilan, persalinan, dan nifas. menurut survei kesehatan daerah Angka Kematian Ibu di Provinsi Jawa Tengah tahun 2007 adalah 20 orang dengan jumlah kelahiran hidup 24.176 orang (Depkes RI,2008)

Penyebab langsung kematian ibu terkait kehamilan dan persalinan terutama adalah perdarahan (28 persen), eklamsi (24 persen), infeksi (11 persen), partus lama (5 persen), dan abortus (5 persen) (Dpkes RI,2010). Perdarahan merupakan penyebab AKI yang paling utama, salah satu penyebab perdarahan adalah placenta previa, Di Amerika placenta previa menyumbangkan mortalitas perinatal sebesar 2-3\% dan Mortalitas maternal sebesar $0,03 \%$. Angaka kejadian plasenta previa adalah $0,3-0,5 \%$ dari semua kelahiran, resiko plasenta previa berhubungan dengan usia ibu saat hamil, kejadiannya meningkat sebagai berikut Usia 12-19 tahun - 1\%, usia 20-29 tahun $0,33 \%$, usia $30-39$ tahun $-1 \%$, usia di atas 40 tahun - 2\% (manuaba, 2006). Di Rumah Sakit Dr. Cipto Mangunkusumo frekuensi plasenta previa pada primigravida yang berumur lebih dari 35 tahun kira-kira 2 kali lebih besar dibandingkan dengan primigravida yang berumur kurang dari 25 tahun, pada para 3 atau lebih yang berumur lebih dari 35 tahun kira-kira 3 kali lebih besar dibandingkan dengan para 3 atau lebih yang berumur kurang dari 25 tahun (Prawirohardjo, 2009). Data kejadian placenta previa di Rumah Sakit Soeradji Tirtonegoro Klaten pada tahun 2010 terdapat 122 kasus.

\section{METODE PENELITIAN}

Jenis penelitian ini merupakan penelitian observasional. Sedangkan desain penelitian adalah ex post facto yaitu suatu penelitian yang telah diteliti oleh Anna Mariana tahun 2010 dengan judul "Kejadian Placenta Previa di Rumah Sakit Umum Pusat Soeradji Tirtonegoro" Sampel pada penelitian ini adalah ibu dengan placenta previa dari bulan Januari - Desember 2010 sebanyak 122 orang. Teknik pengambilan sampel yang digunakan adalah sampling jenuh. Penelitian dilakukan di Rumah Sakit Umum Pusat Soeradji Tirtonegoro Klaten. Instrumen penelitian yang digunakan dalam penelitian ini adalah catatan medik pasien yang digunakan untuk memperoleh data yang diperlukan. Analisis data yang digunakan untuk mengetahui pengaruh usia ibu hamil dengan kejadian plasenta previa dilakukan analisis regresi linear sedrehana dengan menggunakan program Statistical Product and Service Solution (SPSS) 18.00 for Windows.

\section{HASIL PENELITIAN}

Tabel 1

\begin{tabular}{ccccc}
\multicolumn{3}{c}{ Deskripsi Statistik Usia Ibu hamil } \\
\multicolumn{3}{c}{ dengan Kejadian Placenta Previa } \\
\hline Variabel & Mean & ST Dev & $\mathrm{N}$ & $\begin{array}{c}\text { Pearson } \\
\text { Correlation } \\
\text { kejadian placenta } \\
\text { previa - usia }\end{array}$ \\
\hline $\begin{array}{c}\text { Kejadian } \\
\begin{array}{c}\text { Placenta } \\
\text { previa } \\
\text { Usia }\end{array}\end{array}$ & 6,4211 & 5,04773 & 19 & 0,938 \\
\hline
\end{tabular}


Dari tabel 1 dapat dilihat bahwa rata-rata kejadian placenta previa dari 19 kelompok usia adalah 6,42 kejadian sedangkan rata- rata usia ibu melahirkan placenta previa adalah 28 tahun. Hubungan kejadian placenta previa dengan usia ibu melahirkan signifikans karena nilai $\mathrm{p}=0,000$ atau $\mathrm{p}<0,05$, dan nilai $\mathrm{r}=0,938$ menunjukan korelasi yang kuat.

\section{Tabel 2}

\section{Variasi kejadian Placenta Previa}

\begin{tabular}{|l|r|r|r|r|}
\hline Model & Rodel Summary \\
\hline 1 & $.938^{\mathrm{a}}$ & $\mathrm{R}$ Square & $\begin{array}{c}\text { Adjusted } \\
\text { R Square }\end{array}$ & $\begin{array}{r}\text { Std. Error of } \\
\text { the Estimate }\end{array}$ \\
\hline
\end{tabular}
a. Predictors: (Constant), Usia
b. Dependent Variable: Kejadianplacenta

Dari tabel 2 dapat dilihat Nilai $\mathrm{R}=$ 0,893 dan $\mathrm{R} X \mathrm{R}=\mathrm{R}$ Square $=0,872$ menunjukan bahwa 0,872 atau $87,2 \%$ variasi kejadian placenta previa dipengaruhi oleh oleh variable usia ibu, sementara sisanya dipengaruhi oleh kejadian-kejadian lain. Standard error of estimated $=1,806$ tahun lebih kecil dari standard deviasi 5,05, maka regresi usia ibu hamil dengan kejadian placenta previa layak digunakan.

\section{Tabel 3}

\section{Pengaruh Usia Ibu Hamil Terhadap Kejadian Placenta Previa}

\begin{tabular}{|c|c|c|c|c|c|c|}
\hline \multicolumn{7}{|c|}{ ANOVA ${ }^{b}$} \\
\hline Model & & $\begin{array}{l}\text { Sum of } \\
\text { Squares }\end{array}$ & $\mathrm{df}$ & Mean Square & $\mathrm{F}$ & \\
\hline 1 & Regression & 403.154 & 1 & 403.154 & 123.540 & $.000^{\mathrm{a}}$ \\
\hline & Residual & 55.477 & 17 & 3.263 & & \\
\hline & Total & 458.632 & 18 & & & \\
\hline
\end{tabular}

Pada Tabel 3 yaitu Anova nilai $\mathrm{F}$ $=123,540$ dengan $\mathrm{p}=0,000$ oleh karena $\mathrm{p}$ $<0,05$ maka regresi dapat digunakan untuk mempresiksi kejadian placenta previa, atau secara bersama-sama variable bebas usia ibu hamil dapat berpengaruh terhadap kejadian placenta previa pada taraf kepercayaan $95 \%$

\section{Tabel 4}

Coefisien Corelasi

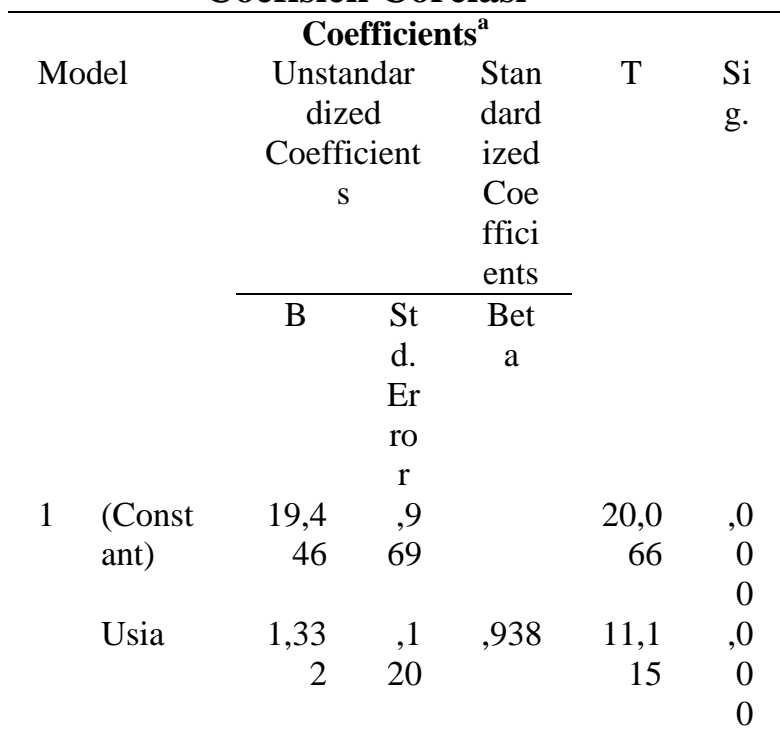

a. Dependent Variable: kejadian placenta

Pada tabel 4 Coeficients dapat dilihat bahwa nilai B constant 19,446 bila usia ibu hamil diabaikan maka kejadian placenta previa 19,446. Nilai B usia adalah 1,332 menyatakan bahwa bila setiap penambahan usia 1 tahun kejadian placenta previa bertambah 1,332 kejadian. Berdasarkan nilai B constant dan B Usia maka dapat dibuat persamaan regresi.

$$
\begin{aligned}
& \mathrm{Y}=\mathrm{a}+\mathrm{bX} \\
& \mathrm{Y}=19,446+1,332 \mathrm{X}
\end{aligned}
$$

Keterangan : $\mathrm{Y}=$ kejadian placenta previa, $\mathrm{a}=$ konstanta

$\mathrm{X}=$ usia

Pada tabel 4 dapat dilihat nilai $\mathrm{t}$ hitung usia adalah 11,115. Pada derajat kebebasan $(\mathrm{df})=\mathrm{N}-2=19-2=17$, nilai $\mathrm{t}$ table pada taraf kepercayaan $95 \%$ (signifikansi 0,05) adalah 1,740, Oleh karena nilai hitung lebih besar dari nilai 
table maka koeficien regresi signifikan, atau usia berpengaruh terhadap kejadian placenta previa.

Berdasarkan nilai probabiltas $\mathrm{X}: \mathrm{p}$ $=0,000$, maka usia secara signifikan berpengaruh terhadap kejadian placenta previa.

\section{PEMBAHASAN}

Dari Hasil penelitian didapatkan bahwa ada hubungan anrata usia ibu hamil dengan kejadian placenta privia, $p=0,000$ ( $\mathrm{p}<0,05)$, dengan hasil $\mathrm{RXR}=0,872$ atau $87,2 \%$ kejadian placenta previa dipengaruhi oleh usia ibu hamil serta hubungannya sangat kuat $r=0,938$. Hasil penelirian ini sesuai dengan teori sheiner (2001) Ibu dengan usia lebih tua, risiko plasenta previa berkembang 3 kali lebih besar pada perempuan di atas usia 35 tahun dibandingkan pada wanita di bawah usia 20 tahun. Hasil penelitian Wardana (2007) menyatakan usia wanita produktif yang aman untuk kehamilan dan persalinan adalah 20-35 tahun. Diduga risiko plasenta previa meningkat dengan bertambahnya usia ibu, terutama setelah usia 35 tahun. Plasenta previa merupakan salah satu penyebab serius perdarahan pada periode trimester ke III. Hal ini biasanya terjadi pada wanita dengan usia lebih dari 35 tahun (Varney, 2006). Prevalensi plasenta previa meningkat 3 kali pada umur ibu > 35 tahun. Plasenta previa dapat terjadi pada umur diatas 35 tahun karena endometrium yang kurang subur dapat meningkatkan kejadian plasenta previa (Manuaba, 2008). Hasil penelitian Wardana (2007) menyatakan peningkatan umur ibu merupakan faktor risiko plasenta previa, karena sklerosis pembuluh darah arteli kecil dan arteriole miometrium menyebabkan aliran darah ke endometrium tidak merata sehingga plasenta tumbuh lebih lebar dengan luas permukaan yang lebih besar, untuk mendapatkan aliran darah yang adekuat.

\section{KESIMPULAN DAN SARAN:}

$87,20 \%$ kejadian placenta previa dipengaruhi oleh usia ibu saat hamil dan pengaruhnya sangat kuat yaitu $r=0,938$. Setiap penambahan usia ibu saat hamil 1 tahun kejadian placenta previa bertambah 1,332 kejadian. Kepada Bidan pada setiap kegiatan Posyandu agar selalu memberikan penyuluhan tentang usia reproduksi sehat kepada ibu-ibu yang hadir di posyandu. Kepada ibu yang sedang hamil diusia yang bukan merupakan usia reproduksi sehat yaitu usia di atas 35 tahun agar selalu memeriksakan kehamilannya secara rutin.

\section{DAFTAR RUJUKAN}

Budiarto E. 2002. Biostatistika untuk Kedokteran dan Kesehatan Mayarakat. Jakarta: EGC.

Depkes RI (2008). Profil Kesehatan Indonesia tahun 2008.

Manuaba IBG. 2008. Ilmu Kebidanan, Penyakit Kandungan \& Keluarga Berencana Untuk Pendidikan Bidan. Jakarta: EGC.

Sastrawinata. 2005. Metodologi Penelitian Kesehatan. Jakarta: Rineka Cipta

Varney H. 2007. Buku Ajar Asuhan Kebidanan vol. 1. Jakarta: EGC. 